\title{
Household level paddy storage and insect infestation of paddy, maize and mungbean in Anuradhapura district of Sri Lanka
}

\author{
J.M.P. Kumari ${ }^{1}$, L.K.W. Wijayaratne ${ }^{2 *}$, N.W.I.A. Jayawardena ${ }^{1}$ and W.C.P. Egodawatta ${ }^{2}$
}

${ }^{1}$ Department of Animal and Food Sciences, Faculty of Agriculture, Rajarata University of Sri Lanka, Anuradhapura (50000), Sri Lanka.

${ }^{2}$ Department of Plant Sciences, Faculty of Agriculture, Rajarata University of Sri Lanka, Anuradhapura (50000), Sri Lanka.

\section{Correspondence:}

*wollylk@yahoo.com

(iD https://orcid.org/0000-0003-3748-040X

Funding Acknowledgement: Rajarata University of Sri Lanka (Grant No. RJT/RP\&HDC/2015/Agri/R/09).

DOI: http://doi.org/10.4038/sljae.v2i2.39

\begin{abstract}
The augmented losses occur during the storage of grains but details on such information is minimum under Sri Lankan conditions. Unawareness of relevant and updated information on these losses prevents the adoption of appropriate remedial measures for the protection of these stored grains. Therefore, the current study was conducted in Anuradhapura district of Sri Lanka to determine the types of household-level storage structures/places used, grain losses occurred in those structures/places and nature of insect infestation of stored paddy, maize and mungbean. A questionnaire survey was conducted throughout Anuradhapura district using farmer families. Four main structures/places used in grain storage in different divisional secretariats were identified. The storage structures/places used from the highest to lowest frequency were room inside house, kitchen, room outside the house and temporary hut. Sitophilus oryzae was the most abundant stored pest followed by Sitotroga cerealella, Tribolium castaneum and Rhyzopertha dominica. The structures/places of grain storage and abundance of insect species were different among divisional secretariats. This study discloses the structures/places of grain storage, their frequency of use as well as the main insect species responsible for grain losses in the Anuradhapura district of Sri Lanka.
\end{abstract}

Keywords: Anuradhapura district, grain storage, storage loss, stored-product insects, storage structures 


\section{Introduction}

The food losses occurred due to the damage caused by insects during storage are quite high and of numerous types (Wijayaratne et al. 2018). The losses caused by insects to the stored food vary from $10 \%$ of the harvest in temperate countries to approximately $50 \%$ in the humid tropics (Wijayaratne et al. 2018). Among the variety of losses caused by insects during storage, the damage occurred in cereal grains, pulses and their processed products is of great importance due to their increased role in human and animal nutrition (Hagstrum and Subramanyam 2006; Wijerathne et al. 2020). The quantitative and qualitative damage to the stored grains by insects include loss of weight, nutrients and seed viability; contamination with live/dead insects, their body parts and excreta; webbing of grains; health risks on consumers (Hill 1990) including allergenic reactions (Larson et al. $2008 a, b)$. These reduce the market value of stored grains and thus cause economic losses (Hagstrum and Subramanyam 2006).

Rice is consumed by people across the world (Cuevas et al. 2016) and is the staple food in Sri Lanka (Waisundara 2020). In Sri Lanka, total paddy production in the Yala season 2019 was 1,519,475 MT. Out of this, Anuradhapura district produced 132,103 MT of paddy (8.7\% of total production). In
2019/2020 Maha season 752,248 ha was under paddy cultivation out of which 118,902 ha $(15.8 \%)$ belonged to Anuradhapura district. Furthermore, out of the total paddy production of $3,196,752 \mathrm{MT}$ in the country, Anuradhapura district produced 530,356 MT (16.6\% of total production) (Department of Census and Statistics 2019). Out of the total paddy production in Anuradhapura district, nearly $13 \%$ is declared to exceed the requirement of the consumers of the district (Department of Census and Statistics 2019). As paddy cultivation is seasonal, the surplus production is stored to ensure its availability during off seasons. Paddy, other field crops and pulses stored at the household level in Anuradhapura district undergo quantitative and qualitative losses (Kumari et al. 2020). As highlighted in this recent report, the updated information of storage methods and insects damaging these stored commodities are unavailable. The last record on the storage structures of paddy and the losses caused by insects to the stored paddy in Sri Lanka has been nearly two decades ago (Palipane 2001) and thus outdated. Therefore, the objectives of this study were to identify the structures/places used at the household level in Anuradhapura district to store paddy and other main crops, the grain losses in those structures/places and to 
determine the insect infestation occurred during storage.

\section{Materials and Methods}

\section{Data Collection}

The data were collected through a survey conducted in Anuradhapura district as described in Kumari et al. (2020). Data were collected from all the divisional secretariats (22) during the Maha 2015/2016. They were Galenbidunuwewa, Galnewa, Horowpothana, Ipalogama, Kahatagasdigiliya, Kebithigollawa, Kekirawa, Medawachchiya, Mihintale, Nachchaduwa, Nochchiyagama, Nuwaragampalatha-Central, Nuwaragampalatha-East, Padaviya, Palagala, Palugaswewa, Rajanganaya, Rambaewa, Thalawa, Thambuththegama, Thirappane and Vilachchiya. A sample of 20 farmer families in each divisional secretariat were interviewed. In total, 440 farmer families were included in the survey. A pretested questionnaire set to unveil the required information from farmers to meet the objectives was used in the survey. The samples were obtained from different storage structures/places using the sampling probe. The identification of insects in the respective stored commodities was done at the location of data collection by referring to the body characteristics of insects and their dead specimens, and later confirmed using photographs of different insect species reported in stored food commodities (Sinha and Watters 1985; Hill 1990).

\section{Data analysis}

The experimental design used in the study was completely randomized design. The quantity of stored grain loss was analysed as percentage loss. Frequency analysis using Proc Freq was used to analyse qualitative losses (SAS Institute 20022008). Chi-square test was used to determine independence of each stratum and to compute measures of association. The Fisher's exact test was used for test stratum wise significances. The significance was tested at $\alpha=0.05$.

\section{Results and Discussion}

\section{Storage Structures for Paddy}

Four main types of small-scale/farmer-level storage structures/places used in paddy storage were found in different DS divisions in Anuradhapura district. They were room inside the house, room outside the house, temporary hut and kitchen. A room inside the house used for the storage of paddy was mostly found in Ipalogama (91\%) whereas the lowest usage was in Nochchiyagama (55\%) (Fig. 1). The highest usage of the kitchen was in Nochchiyagama (40\%) and the lowest in Ipalogama, Medawachchiya and Nachchaduwa (each 9\%) (Fig. 2). The 
room outside the house used for storage of paddy was highest in Rambewa (29\%) whereas the lowest in Kekirawa, Medawachchiya, Nochchiyagama, Nuwaragampalatha East, Thambuththegama, Thalawa and Vilachchiya (each 5\%) (Fig.3). Temporary huts were used as storage structures in Galnewa, Kebithigollewa, Mihintale, Thambuththegama (each 5\%) (Fig. 4). It is noted that room inside the house and kitchen were used in all the 22 DS divisions. Of them, the most popular structure was the room inside the house. Furthermore, room outside the house was used only in 13 (59\%) divisions whereas only four (18\%) divisions used temporary hut as a storage structure for paddy. The reason for variation in the use of these different structures/places needs to be sought in a future research.

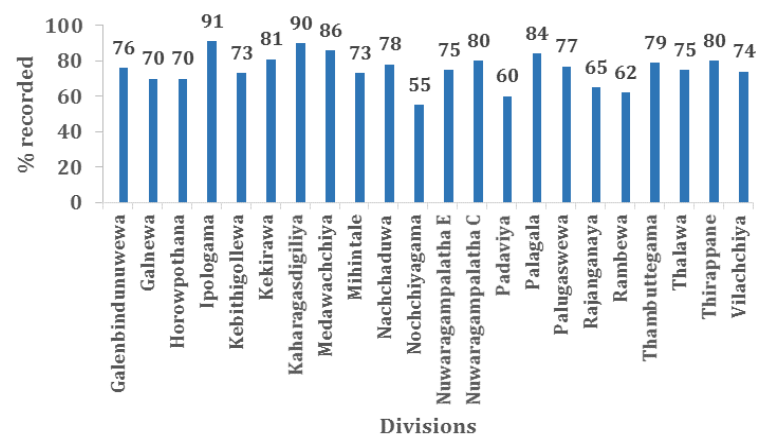

Figure 1. Percentage of families used a room inside house for storage of paddy in different divisional secretariats in Anuradhapura district.

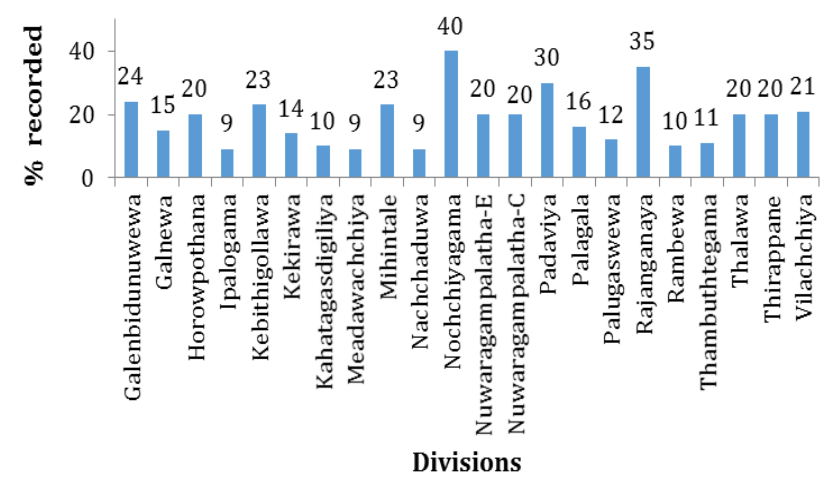

Figure 2. Percentage of families used the kitchen for storage of paddy in different divisional secretariats in Anuradhapura district.

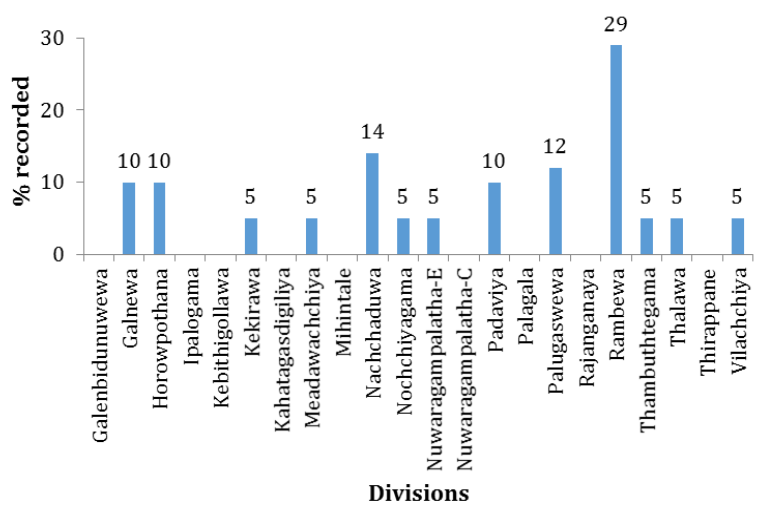

Figure 3. Percentage of families used a room outside house for storage of paddy in different divisional secretariats in Anuradhapura district.

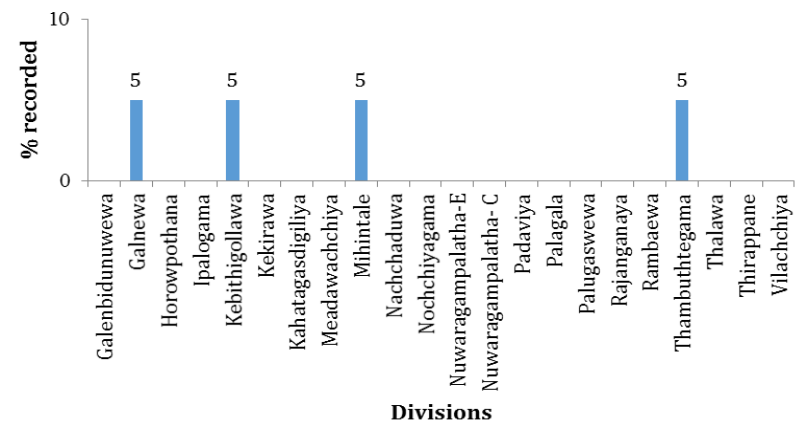

Figure 4. Percentage of families used a temporary hut for storage of paddy in different divisional secretariats in Anuradhapura district.

Palipane (2001) suggested the possibility of using improved storage structures such as clay bissa and gunny bissa to maintain the high quality of paddy. However, traditional 
storage structures such as Atuwa or bissa were not found to store paddy in Anuradhapura district during the present study. Proctor (1994) reported aerial storage, storage on the ground, drying floors, open timber platforms, storage baskets (cribs) made exclusively of plant materials, earthenware pots, solid wall bins and underground storage as grain storage methods in developing countries. These practices were also not reported from Anuradhapura district during the present study.

The storage losses were higher in the temporary hut $(8 \%)$ than in the other three structures/places: kitchen (5.7\%), room inside the house (5.7\%) and room outside house (2.1\%) (Fig. 5). As reported separately (Kumari et al. 2020), the average loss of unmilled rice found in this study was $5.6 \%$ which approximates the previous finding (Palipane 2001). Furthermore, Dharmasena and Abeysiriwardena (2003) reported $2.6 \%$ loss of stored grain in the 'clay bissa,' an indigenous outdoor bin in Sri Lanka. This approximates the losses found in outdoor structures $(2.6 \%)$ in the current study. The possible reason for the grain losses in these structures may be the exposure to external environmental conditions such as rain fall (moisture) and damage by animals. However, this needs further investigations.

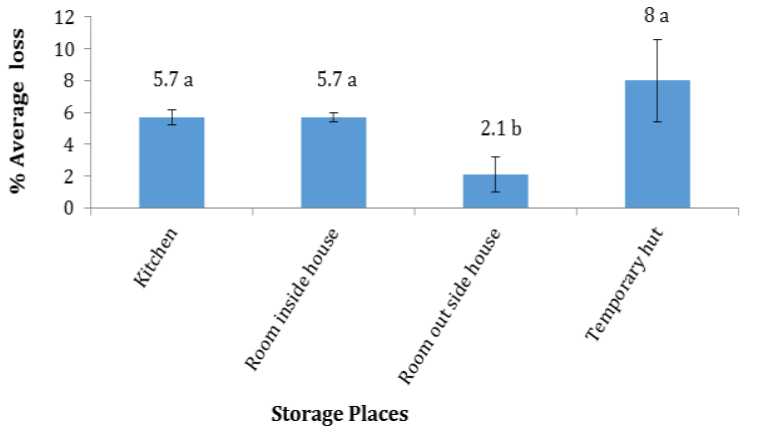

Figure 5. Percentage loss of paddy stored in different storage structures/places.

a. Mean values followed by the same letter are not significantly different at 0.05 probability level.

\section{Insect Species Infesting Stored Crop Produce}

\section{Insects of Stored Paddy}

Four insect species were recorded in stored paddy: Tribolium castaneum (Red flour beetle), Sitophilus oryzae (Rice weevil), Rhyzopertha dominica (Lesser grain borer), and Sitotroga cerealella (Angoumois grain moth). The highest occurrence of $T$. castaneum was in Rambewa (38\%) whereas Thambuttegama recorded the lowest $(0 \%)$ (Fig. 6). For S. oryzae, the highest and the lowest percentage of infestations were recorded in Padaviya (81\%) and Nachchaduwa (14\%), respectively (Fig. 7). For $R$. dominica, the highest infestation was in Palagala (37\%) and the lowest in Thambuttegama (0\%) (Fig. 8). Sitotroga cerealella was most abundant in Palagala division (63\%), and lowest in Padaviya (10\%) (Fig. 9). Overall, the highest abundance was $S$. oryzae and occurrence 
decreased in the order as $S$. cerealella, $T$. castaneum and $R$. dominica.

Dharmasena and Abeysiriwardena (2003) reported $S$. cerealella, $S$. oryzae and $T$. castaneum as major pests of stored paddy in Sri Lanka. Qayyum (1974) reported 23 insect species damaging the stored grain in Pakistan, and Trogoderma granarium, $R$. dominica, $S$. oryzae, $T$. castaneum, $S$. cerealella and Callosobruchus chinensis as the most important species. San (2014) recorded S. oryzae and Sitophilus granarius in rice, wheat, maize, and cereals in Myanmar. The findings of current research are also in agreement with the above findings. Future research can be designed to find out possible reasons for the variation of insect infestation levels in different storage structures/places.

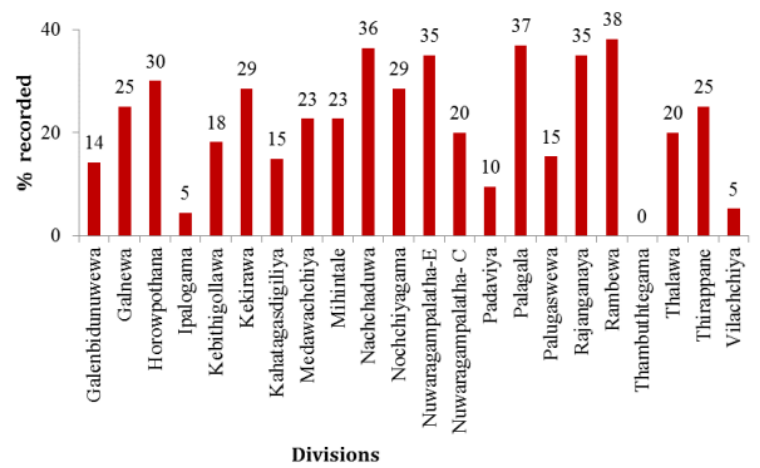

Figure 6. Percentage of farmer families having stored paddy infested with Tribolium castaneum in different DS divisions in Anuradhapura district.

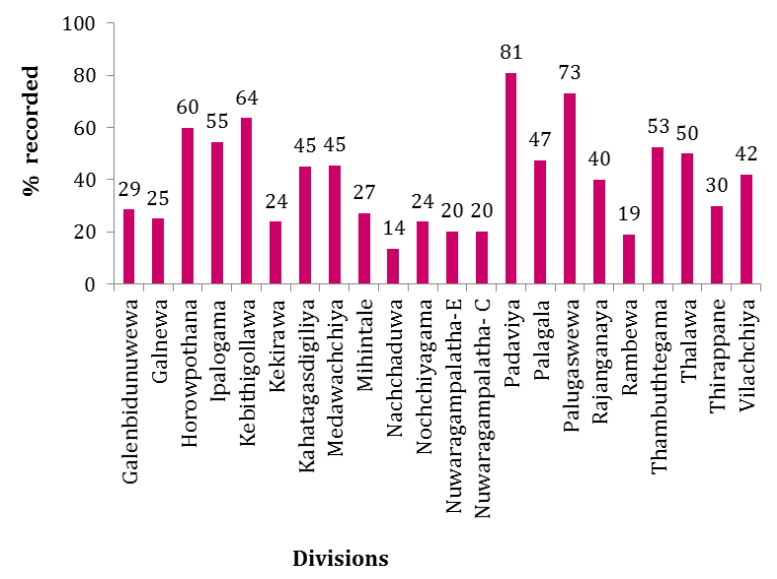

Figure 7. Percentage of farmer families having stored paddy infested with Sitophilus oryzae in different DS divisions in Anuradhapura district.

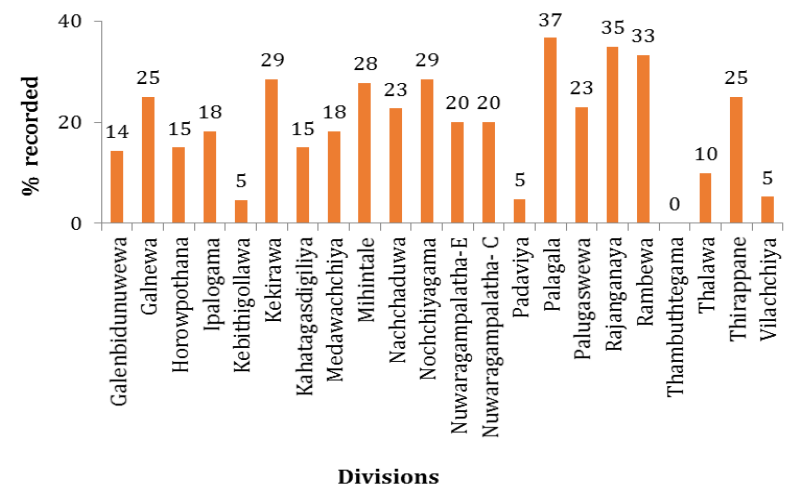

Figure 8. Percentage of farmer families having stored paddy infested with Rhyzopertha dominica in different DS divisions in Anuradhapura district.

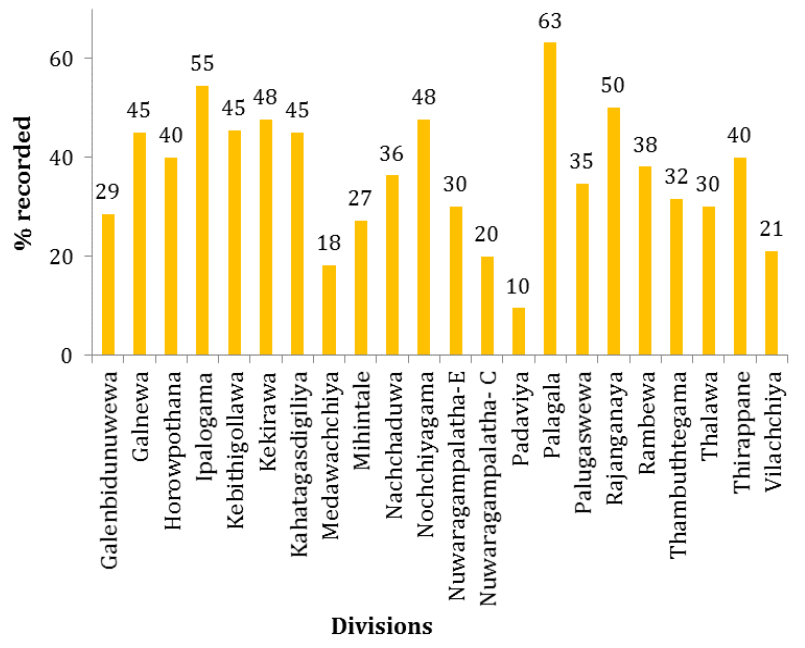

Figure 9. Percentage of farmer families having stored paddy infested with Sitotroga cerealella in different DS divisions in Anuradhapura district. 


\section{Insects of maize and mungbean}

The highest percentage of $S$. oryzae in maize occurred in Horowpothana (100\%) whereas the lowest percentage was in Vilachchiya (20\%). For T. castaneum, the highest and the lowest infestations were recorded in Vilachchiya (80\%) and Kahatagasdigiliya (33\%), respectively. For $R$. dominica, the highest and the lowest percentages were recorded in Galenbidunuwewa (100\%) and Kaharagasdigiliya (33\%), respectively (Fig. 10). Pulse beetle was recorded in stored mungbean in Rajanganaya and Rambewa only (Fig. 11).

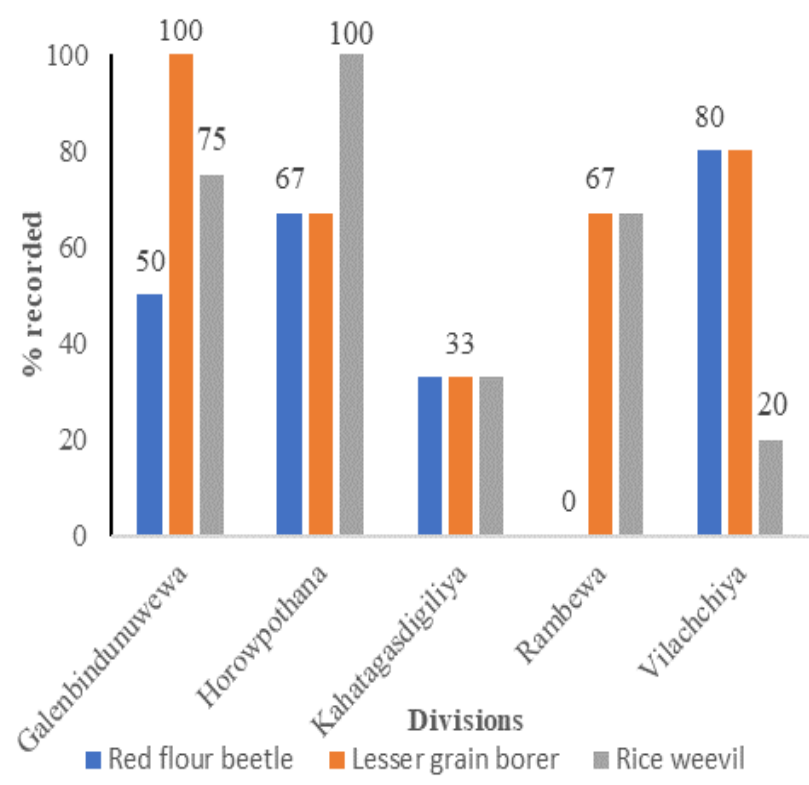

Figure 10. Percentage of farmer families having insect infestation in stored maize in Anuradhapura district.

As reported by Kumari et al. (2020), maize was found to have been stored only in Galenbindunuwewa, Horowpothana,
Kaharagasdigiliya, Rambewa and Vilachchiya. Accordingly, in the present study, insect infestation in stored maize was observed only in those five divisions. Similarly, mungbean was found to have been stored only in Rajanganaya and Rambewa (Kumari et al. 2020). Thus, in the present study Callosobruchus species that infest stored pulses were found only in those two divisions.

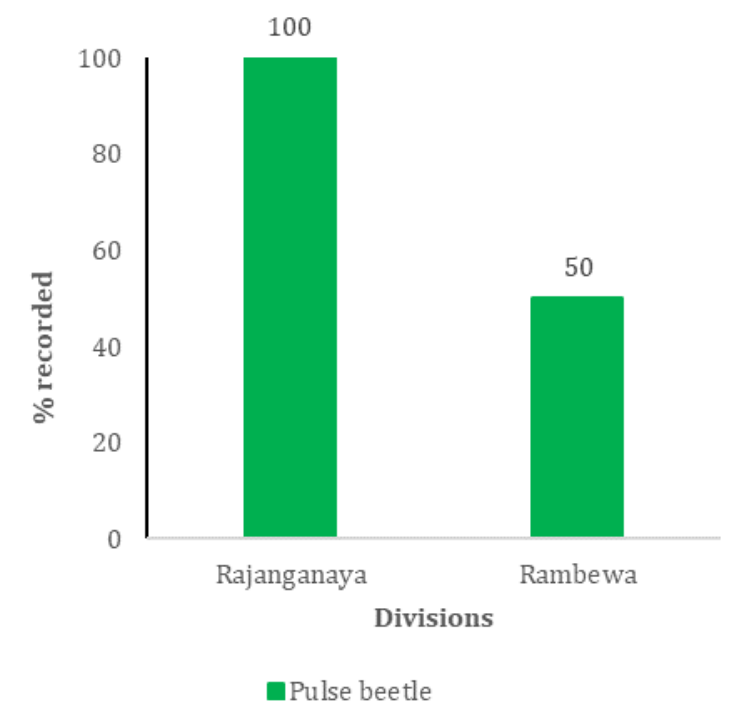

Figure 11. Percentage of farmer families having Callosobruchus sp. in stored mungbean in Anuradhapura district.

Dick (1988) reported that in Africa large number of insect species infests stored maize. Among them, Prostephanus truncatus (Larger grain borer), Sitophilus spp. and $S$. cerealella are the most important maize pests. Prostephanus truncatus was recorded from stored maize and dried cassava roots in Latin America and parts of sub-Saharan Africa. Danso et al. (2018) reported the prevalence of $S$. 
cerealella and T. castaneum in stored maize in Ghana. Paim et al. (2018) reported that $R$. dominica infests stored maize in Angola. Several bruchid species attack cereals and pulses in the storage (Mbata et al. 2009). In the current study, pulse beetle was recorded from stored mungbean in Anuradhapura District. Yongxue (1998) reported $C$. chinensis in stored greengram in China. The pulse beetles (Callosobruchus spp.) have also been reported from the Philippines, Japan, Indonesia, Sri Lanka, Burma and India in stored pulse crops (Lal and Raj 2012). These agree with the current finding from Anuradhapura, Sri Lanka.

Poor sanitation is a major reason for insect infestation during storage of crops (Hagstrum and Subramanyam 2006). During this survey, certain factors that favour the development of insects in storage facilities were detected. Some of these include the inadequate attention on grain sanitation, spread of grains outside the storage structures/places and exposure of grains in these structures/places to the outside environment. The exact contribution of these factors on the development of insect populations in grain storage facilities in Anuradhapura district should properly be explored in a future study. Furthermore, it is suggested to expand the present study in other districts of Sri Lanka to identify the sources and degree of insect infestation of different storage systems.

\section{Conclusions}

In Anuradhapura district of Sri Lanka, the harvested paddy is stored at household level, from most to least popular, in a room inside the house, kitchen, room outside the house and temporary hut. The insect species that infest stored paddy, from most to least abundance, are $S$. oryzae, $S$. cerealella, T. castaneum and $R$. dominica. Future research may explore factors contributing the insect infestation in these storage structures/places, underlying reasons for the differences observed in infestation levels and appropriate methods to minimize damage caused by insects to the stored grains.

\section{Conflicts of Interest:}

The authors have no conflicts of interest regarding this publication.

\section{References}

Cuevas R P, Pede V O, McKinley J, Velarde 0, Demont M (2016) Rice grain quality and consumer preferences: a case study of two rural towns in the Philippines. PloS One 11, e0150345.

Danso J K, Osekre E A, Opit G P, Manu N, Armstrong P R, Arthur F H, Campbell J F, Mbata G N, McNeill S G, 2018. Insect pests 
and fungal pathogens in maize stored in Ghana. In: Adler C S, Opit G, Furstenau B, Muller-Blenkle C, Kern P, Arthur F H, Athanassiou C G, Bartosik R, Campbell J, Carvalho M O, Chayaprasert W, Fields P, Li Z, Maier D, Nayak M, Nukenine E, ObengOfori D, Phillips T, Riudavets J, Throne J, Scholler M, Stejskal V, Talwana H, Timlick B, Trematerra P (eds.), Proceedings of the 12th International Working Conference on Stored Product Protection, 7-11 October, 2018, Berlin, Germany, Julius Kühn-Institut, Berlin, Germany, 27-31.

Department of Census and Statistics, 2019. http://www.statistics.gov.lk/Agriculture/St aticalInformation/rubpaddy. Retrieved on: November 25, 2020.

Dharmasena C M D, Abeysiriwardena D (2003) Effect of variety, grain moisture and packing material on weight and storage pests of rough rice during storage. Annals of the Sri Lanka Department of Agriculture 5:57-67.

Dick K (1988) A review of insect infestation of maize in farm storage in Africa with special reference to the ecology and control of Prostephanus truncatus. The Scientific Unit of the Overseas Development Administration (ODNRI), United Kingdom, 42pp.
Hagstrum D W, Subramanyam B (2006) Fundamentals of Stored-Product Entomology. AACC International, St Paul.

Hill D S (1990) Pests of stored products and their control. CBS Publishers and Distributors (Pvt.) Ltd., London.

Kumari J M P, Wijayaratne L K W, Jayawardena N W I A, Egodawatta W C P (2020) Quantitative and qualitative losses in paddy, maize and greengram stored under household conditions in Anuradhapura district of Sri Lanka. Sri Lankan J. Agri. Ecosys. 2: 99-106.

Lal D, Raj D V (2012) Efficacy of application of four vegetable oils as grain protectant against the growth and development of Callosobruchus maculatus and on its damage. Adv Biores 3: 55-59.

Larson Z, Subramanyam Bh, Herrman, T (2008a) Stored-Product insects associated with eight feed mills in the Midwestern United States. J. Econ. Entomol. 101: 9981005.

Larson Z, Subramanyam Bh, Zurek L, Hermann T (2008b). Diversity and antibiotic resistance of enterococci associated with stored-product insects collected from feed mills. J. Stored Prod. Res. 44: 198-203. 
Mbata G N, Phillips T W, Payton, M E (2009). Effects of cowpea varietal susceptibility and low pressure on the mortality of life stages of Callosobruchus maculatus (Coleoptera: Bruchidae). J. Stored Prod. Res. 45: 232-235.

Paim L, Barros G, Magro A, da Silva E B, Mexia A, Lima A (2018) Insects and fungi in stored maize in Angola. In: Adler C S, Opit G, Furstenau B, Muller-Blenkle C, Kern P, Arthur F H, Athanassiou C G, Bartosik R, Campbell J, Carvalho M O, Chayaprasert W, Fields P, Li Z, Maier D, Nayak M, Nukenine E, Obeng-Ofori D, Phillips T, Riudavets J, Throne J, Scholler M, Stejskal V, Talwana H, Timlick B, Trematerra P (eds.), Proceedings of the 12th International Working Conference on Stored Product Protection, 7-11 October, 2018, Berlin, Germany, Julius Kühn-Institut, Berlin, Germany, 264-268.

Palipane K B (2001) Milling and quality improvement in rice in Abeysiriwardena D S de Z, Dissanayaka D M N, Nugaliyadde L (Eds.) Proceeding of rice symposium, Gannoruwa, Sri-Lanka, 14-15 December 2000.

Proctor D L (1994) Grain storage techniques-Evaluation and trends in developing countries. Food and Agriculture Organization, Rome, Italy, 224pp.
Qayyum H A (1974) Losses caused to stored products by insect pests in Pakistan and measures for their control. http://spiru.cgahr.ksu.edu/proj/iwcspp/pd f2/2/49.pdf. Retrieved on: January 11, 2016.

San, N.N (2014) Incidence of insect pests in some stored crops in Singu township, Mandalay region. http://icmr.crru.ac.th/Journal/Journal\%20 4/7\%20Incidence $\% 20$ of\%20Insect $\% 20$ Pes ts\%20in\%20Some\%20Stored.pdf.

Retrieved on: January 12, 2020.

SAS Institute (2002-2008) The SAS system for windows, release 9.1. Statistical analysis system institute, Cary, NC.

Sinha R N, Watters F L (1985) Insect Pests of Flour Mills, Grain Elevators, and Feed Mills and Their Control. Agriculture Canada Publication, Ottawa.

Waisundara V Y (2020) Traditional functional food of Sri Lanka and their health significance. In Prakash J, Waisundara V, Prakash V (Eds.) Nutritional and Health Aspects of Food in South Asian Countries. Academic Press, 143-158.

Wijayaratne L K W, Arthur F H, Whyard S (2018) Methoprene and control of stored- 
product insects. J. Stored Prod. Res. 76:

161-169.

Wijerathne, K B T, Karunarathne E V U P, Dissanayaka D M S K, Wijayaratne L K W (2020) New food Media for rearing Tribolium castaneum (Herbst) (Coleoptera: Tenebrionidae). Rajarata Univ. J. 5: 41-45.

Yongxue D, Longshu L, Zhimo Z (1998) Development and reproduction of Callosobruchus chinensis (Coleoptera: Bruchidae) on four legume plant seeds. In: Jin, Z.; Liang, Q.; Liang, Y.; Tan, X.; Guan, L. (Eds.), Proceedings of the 7th International Working Conference on Stored-Product Protection, 14-19 October 1998, Beijing, China. Sichuan Publishing House of Science and Technology, Chengdu, China. 